\title{
As formas da cultura em Cidade de Deus, de Paulo Lins
}

\author{
Jefferson Agostini Mello \\ Universidade de São Paulo (São Paulo, Brasil)
}

\begin{abstract}
RESUMO: NO PRESENTE ARTIGO, ANALISAMOS O ROMANCE CIDADE DE DEUS, DE PAULO LINS, ENFATIZANDO O SEU HIBRIDISMO DE FORMAS E RITUAIS QUE PODERÍAMOS CHAMAR DE ARCAICOS OU PRÉ-MODERNOS COM OUTROS DA CULTURA DE MASSA CONTEMPORÂNEA. A HIPÓTESE É A DE QUE OS PRIMEIROS OPERAM NO ROMANCE DE MODO DESLOCADO, PERVERTIDO, AO PASSO QUE OS ÚLTIMOS SERÃO OS MEDIADORES DOS VÍNCULOS DOS PERSONAGENS COM A REALIDADE SOCIAL.
\end{abstract}

ABSTRACT: THE PRESENT ARTICLE TREATS PAULO LINS' NOVEL CITY OF GOD, EMPHASIZING THE WAY IN WHICH IT HYBRIDIZES FORMS AND RITUALS THAT COULD BE TERMED PRE-MODERN - OR ARCHAIC - WITH OTHERS THAT BELONG TO CONTEMPORARY MASS CULTURE. OUR HYPOTHESIS IS THAT THE FORMER OPERATE IN A DISLOCATED OR PERVERTED MANNER, WHEREAS THE LATTER ACT AS MEDIATORS LINKING THE CHARACTERS TO SOCIAL REALITY.

PALAVRAS-CHAVE: CIDADE DE DEUS, PAULO LINS, HIBRIDISMO, CULTURA CONTEMPORÂNEA.

KEYWORDS: CITY OF GOD, PAULO LINS, HYBRIDITY, CONTEMPORARY CULTURE. 


\section{ntrodução}

Uma das qualidades do romance Cidade de Deus (1997), de Paulo Lins, é evidenciar a articulação problemática entre modos tradicionais e pós-modernos de representação e convívio no Brasil contemporâneo. Em termos gerais, a narrativa permite ver que no país o que há de mais up to date da cultura mundializada convive com formas e rituais antigos, que poderíamos chamar de pré-modernos, não se dessem eles no momento atual, ganhando assim outros sentidos e funcionando com outros objetivos, perversos, por assim dizer. Em estágio de capitalismo tardio, dominado pela cultura, serão essas formas híbridas as responsáveis por fazer a ponte entre o sujeito e a realidade. ${ }^{1}$

Ao analisar Cidade de Deus, Vilma Areas realçou elementos de arte que compõem o romance e que o avizinham da épica clássica e de outros gêneros mais elementares. A "épica-bandida", "invadida por outras formas, do relatório científico às fichinhas, passando pelas produções da mídia”, é, da mesma forma, "uma épica-negra ou afro, com Exus e Pombagiras, oráculos e sacrifícios" (1998, p. 151); em outros momentos, como na cena do galo que foge para não servir de almoço para os bandidos, temos o que a autora chama de mock-epic, épica derrisória ou cômica (1998, p. 152). Ainda, Cidade de Deus constitui-se de aspectos estruturais da épica clássica, como a "convencional marcação do passar do tempo como o colorido da aurora", apesar de, na épica-bandida, a aurora vir "metamorfoseada do sangue que tinge de vermelho as águas do rio" (1998, p. 153). Também há ali algo da gesta popular: na terceira parte do romance, em tom lírico, com o foco em Mané Galinha - que se tornaria figura lendária no bairro - relembra-se e se imortaliza a existência desse herói. Finalmente, e se referindo ainda às formas simples, teríamos a saga, pois graças a algumas personagens, "assistimos ao suceder de gerações" (1998, p. 154).

Enquanto Vilma Areas enfatizou as formas tradicionais, Roberto Schwarz, em resenha sobre a obra, desvelou outras matrizes do universo da arte e da cultura utilizadas por Paulo Lins, explicitando então apropriações contempo-

1. O romance estaria em consonância com duas teses de Fredric Jameson: i) a cultura é a forma do capitalismo tardio e é ela própria que intermedeia todas as nossas experiências; ii) dominante, o pósmodernismo mesmo assim incorpora formas residuais e emergentes de produção cultural (JAMESON, 1996, p. 74, p. 31). 
râneas. O crítico chamou a atenção ao aproveitamento do cinema, sobretudo dos filmes de gângsteres, e, comentando o andamento da obra, observou que "no plano direto da movimentação, há a visibilidade realçada, à maneira de filme de ação" (1999, p. 164). Porém, o romancista romperia com a convenção desse tipo de cinema, na medida em que cancelaria o suspense e a grandiosidade épica que lhe são característicos, por meio de desencontros e de mortes acidentais dos vilões e heróis, em um "anticonvencionalismo metódico" (1999, p. 170), o mesmo que é notado na "inesperada insistência na poesia" (1999, p. 169), combinada com "os recursos da letra de samba e uma versão abandidada do trocadilhismo concretista" (1999, p. 169).

Com inspiração nesses estudos, buscaremos mostrar no romance de Paulo Lins uma correspondência entre a mescla de referências tradicionais e pósmodernas - no plano da enunciação - e o modo de ser das personagens, cuja mediação com a realidade social pode ter como base tanto formas culturais antiquadas quanto a lógica cultural do capitalismo tardio (sua música, imagens e marcas), ou ainda, uma mistura das duas. À maneira "compósita" (SCHWARZ, 1990), Paulo Lins parece assim rever uma hipótese de Antonio Candido, em um texto da década de 1970:

[...] na maioria dos nossos países [subdesenvolvidos] há grandes massas ainda fora do alcance da literatura erudita, mergulhando numa etapa folclórica de comunicação oral. Quando alfabetizadas e absorvidas pelo processo de urbanização, passam para o domínio do rádio, da televisão, da história em quadrinhos, constituindo a base de uma cultura de massa. Daí a alfabetização não aumentar proporcionalmente o número de leitores de literatura, como a concebemos aqui; mas atirar os alfabetizados, junto com os analfabetos, diretamente da fase folclórica para essa espécie de folclore urbano que é a cultura massificada. No tempo da catequese os missionários coloniais escreviam autos e poemas, em língua indígena ou em vernáculo, para tornar acessíveis ao catecúmeno os princípios da religião e da civilização metropolitana, por meio de formas literárias consagradas, equivalentes às que se destinavam ao homem culto de então. Em nosso tempo, uma catequese às avessas converte rapidamente o homem rural à sociedade urbana, por meio de recursos comunicativos que vão até a inculcação subliminar, impondo-lhes valores duvidosos e bem diferentes dos que o homem culto busca na arte e na literatura (CANDIDO, 2000, p. 144-145). 
Apesar das semelhanças com os diagnósticos de Antonio Candido, o romance de Paulo Lins sugerirá, como veremos a seguir, que a etapa folclórica, em se tratando de Cidade de Deus, já não é mais possível; igualmente, no caso do sujeito favelado, cujas origens mais imediatas podem ser o campo, o sertão nordestino, e outros espaços pobres do Rio de Janeiro, não se processa a sua conversão rápida à sociedade urbana tecnológica e midiática; ao mesmo tempo em que, por outro lado, dissolvem-se as relações com a cultura anterior, possivelmente mais orgânica.

Em artigo intitulado "Fim de século", Roberto Schwarz assinalou diferenças entre o ciclo anterior da etapa folclórica e o do nacional desenvolvimentismo, assim como refletiu sobre os resultados da expansão urbana em sua forma de neofavela, que o romance de Lins busca apreender.

[...] os novos tempos desagregavam à distância o velho enquadramento rural, provocando a migração para as cidades, onde os pobres ficavam largados à disposição passavelmente absoluta das novas formas de exploração econômica e de manipulação populista.

Afastada de suas condições antigas, posta em situações novas e mais ou menos urbanas, a cultura tradicional não desaparecia, mas passava a fazer parte de um processo de outra natureza. A sua presença sistemática no ambiente moderno configurava um desajuste extravagante, cheio de dimensões enigmáticas, que expressava e simbolizava em certa medida o caráter pouco ortodoxo do esforço desenvolvimentista. Aliás, com a sua parte de simpatia e tolerância, mas também de absurdo e primitivismo, essa mescla do tradicional e do moderno se prestava bem para emblema pitoresco da identidade nacional (SCHWARZ, 1999b, p. 156).

Porém, mesmo que esse "emblema" seja aparentemente viável nos primórdios de uma aglomeração feita aos pedaços como a Cidade de Deus representada por Paulo Lins, na etapa seguinte, do capitalismo financeiro, a mistura do tradicional e do pós-moderno vai em direção oposta, restando dela nada mais do que ruína. Schwarz não desenvolve o argumento, apenas assinala que esta deixa de funcionar como emblema nacional, "para indicar um aspecto comum das industrializações retardatárias, passando a representar um traço característico da cena contemporânea tomada em seu conjunto” (1999, p. 157). 


\section{Arcaísmos}

Vejamos primeiramente como alguns traços arcaicos acabam ajudando a configurar os modos de ser e de agir das personagens, começando pela noção de honra, tal como ela intermedeia a relação entre os sujeitos.

No mundo de Cidade de Deus, o pôr em xeque a honra de alguém terá como consequência imediata a vingança com morte; e jamais o diálogo ou o processo jurídico, como se daria em um espaço devidamente amparado pelo Estado moderno e sob as suas leis. Ressaltemos, contudo, que o peso da honra é mais forte na primeira história, antes do processo de desmanche total da comunidade. Assim, nos primórdios da favela, dois fragmentos aparentemente retirados de notícias de jornal permitem verificar que a quebra dos códigos de honra aos quais as personagens estão identificadas - em alguns casos tal quebra se conjuga com a desobediência ao apartheid racial subentendido naquele mundo - levam-nas a ações brutais, em que estão combinados a raiva, o cálculo, a astúcia e a força.

No primeiro, um bebê branco, recém-nascido, filho de outro homem, branco, é esquartejado pelo homem negro traído, e entregue por ele mesmo à sua mulher, negra, em uma caixa de sapatos. Acompanhando a narração, cálculo e ansiedade se misturam. O homem examina as facas que tem em casa, amola a maior no tanque, acende um cigarro, toma um gole de cachaça. Pensa em voltar atrás, "mas a determinação de fazer a mulher sofrer tinha bases sólidas, pois desde o dia em que vira aquele ser nojento um desejo de vingança se apoderara de seu íntimo". De acordo com a voz narrativa, "ele a pegara caidinha no sereno. Montara-lhe casa, comprara-lhe roupas, mandara-a ao salão para dar um molho naquela carapinha maltratada e a bruta foi meter com outro homem". Agora "imaginava sua mulher escorrendo a língua na cabeça do pau de um branquelo qualquer, arregaçando a buceta para receber um caralho branco, quem sabe até de um paraíba". Assim, "o desespero de imaginar sua mulher gozando com outro o fez procurar dentro dele mesmo a mais cruel das vinganças" (LINS, 1997, p. 80).

No segundo fragmento, outro homem decide "lavar a sua honra". Descobre que sua mulher o trai e arma uma emboscada para pegar o amante.

Deixou o indivíduo aproximar-se para certificar-se de ser realmente o dito-cujo que estava comendo a sua mulher. Ajeitou a foice na mão direita, agachou-se, 
esperou que ele passasse. Saiu nas pontas dos pés pelas suas costas e, com apenas um golpe, decepou-lhe a cabeça. Tirou um saco plástico de dentro do bolso da calça, colocou a cabeça ensanguentada com os olhos esbugalhados no saco, foi para casa e jogou-a no colo da adúltera (LINS, 1997, p. 83).

Nas sociedades arcaicas, como, por exemplo, na Grécia do período heróico, as bases do sujeito são, segundo Moses Finley, a honra e a coragem: "a coragem é a virtude essencial do herói, o seu objetivo essencial. Toda a norma, todo o julgamento e toda a ação, todo o saber-fazer e talento têm por função seja definir a honra, seja realizá-la. A própria vida não poderia fazerlhe obstáculo" (1972, p. 172). Curiosamente, no mundo dos ex-escravos e ex-homens livres, o remédio para o desrespeito ao patriarca, para a traição, é sempre a vingança mortal, com cálculo, astúcia e requintes de crueldade, a qual reitera, publicamente, o valor do homem, no caso o cabra-macho, e restringe a resolução dos problemas ou ao núcleo familiar. Mas, se na épica grega é a armadura do inimigo que testemunha ao público a valentia do herói, no mundo de Cidade de Deus, na épica negra (AREAS, 1998), é "a cabeça da vítima que desempenha essa função gloriosa", como, segundo Finley, "entre os povos mais primitivos" (1972, p. 181).

Há ainda, no romance, outros rituais de expiação que, por sua vez, também se relacionam, de forma indireta, ao arcaísmo grego. Cabeção é um policial corrupto, cujos pedaços da biografia são fornecidos ao leitor pela técnica do discurso indireto livre, à medida que ele caminha para a morte. Ficamos sabendo que a mulher o abandonou, passara fome na infância, no fundo não gostava de ser policial, foi dono de bar, comeu do lixo, o filho morreu de tuberculose, tinha mais de trinta crimes nas costas, "mas a maioria era de crioulos", o pai batia na mãe, o padrasto também, teve puta na zona, orgulhava-se de ter sustentado a família tendo o pênis como instrumento de trabalho, sua família foi toda de cabra-macho. Após lembrar-se do passado, Cabeção é morto, pelas costas, por um bandido, cujo irmão ele matou. Seu corpo é colocado numa carroça, num cortejo em que os moradores cospem, xingam, atiram pedras, dão pauladas, despejam latas de lixo e atiram no defunto, segundo o narrador, "tornando mais rubro o crepúsculo de outubro" (LINS, 1997, p. 173-175). Além da marcação do momento do dia e da estação do ano, típica da Épica, esse ritual em torno do cadáver do policial corrupto remete a uma 
importante passagem da Ilíada, de Homero. Bem ao final do texto épico, logo após Aquiles ter matado Heitor, os soldados gregos passavam pelo corpo do guerreiro, ferindo-o. Segundo a narrativa, "golpes seguidos lhe deram" (1991, p. 340). Em seguida, furam-lhe os tendões, por onde se passa uma tira de couro de boi que o prende à uma carroça, "deixando a cabeça tocar o chão duro" enquanto esta se movimenta (1991, p. 340). ${ }^{2}$

Por fim, outro relato de despedaçamento corporal ressurge nas últimas páginas do romance, por meio da personagem Otávio, um assassino em série que teria a proteção de Exu. No entanto, ao contrário dos outros, temos aqui um ato individual, gratuito, que nem se coaduna com a noção de honra do criminoso, nem com uma revolta da comunidade. O primeiro que Otávio mata é Jacarezinho, cujo corpo é desmembrado com um facão. Após enterrálo na cova, feita, aliás, pelo próprio Jacarezinho, Otávio "foi até os pés da figueira mal-assombrada, acendeu sete velas, sentou em cima da cova, retirou um baseado do bolso, acendeu e fumou sem muita pressa" (LINS, 1997, p. 540). A segunda vítima de Otávio é um homem que traíra a mulher e de quem esta desejava vingança. Como fez com Jacarezinho, Otávio exigiu que o homem cavasse a própria sepultura (a mesma em que jazia a primeira vítima) e retalhou seu corpo com facão, repetindo o ritual das velas e do baseado. E mesmo depois das guerras do tráfico terem praticamente terminado, Otávio continuou colocando corpos no mesmo buraco, chegando a trinta e, "quando não os matava, cortava-lhes as mãos a golpes de machadada" (LINS, 1997, p. 543).

Contudo, vale notar que na obra de Paulo Lins esses ecos de arcaísmo ganham uma releitura nada convencional, pois estão longe de dar sentido ou coerência aos espaços em que ocorrem. Talvez isso aconteça porque nesses universos não há de fato uma comunidade, um agrupamento mais ou menos coeso à qual essas formas façam referência, mas apenas sujeitos cujas origens,

2. Não se trata de afirmar que Lins retoma Homero conscientemente. O que pode estar em jogo aqui é antes o que Northrop Frye assinala como o retorno do modo ficcional mítico no modo irônico. Nesta etapa, que corresponde à estética do modernismo, voltariam, segundo Frye, os mitos e ritos das sociedades arcaicas, "cerimônias sacrificiais e deuses agonizantes". Tal tendência, que aparece na hipótese de Vilma Areas, de retomada da épica clássica em Paulo Lins, projetaria também, uma fragmentação cada vez maior do corpo humano, e remontaria às imagens demoníacas do canibalismo que incluem o que "tecnicamente se conhece como sparagmós, ou despedaçamento do corpo sacrificial” (FRYE, 1973, p. 150). 
interesses e projetos se conectam apenas lateralmente. Seja como for, o arcaico acaba funcionando, mas de maneira perversa, pois faz com que as "comunidades" permaneçam dentro dos seus limites, uma vez que o substituto moderno do rito sacrificial, que seria a lei, também não parece fazer sentido para a população pobre do romance. As personagens vivem então em circuitos eternos de vingança, revoltando-se não contra o governo que a jogou nas margens da civilização, mas contra ela mesma, dentro da qual acredita estar a origem de toda a sua destruição. É verdade que formas tradicionais ou populares, tais como a música (o samba), no início da comunidade representada em Cidade de Deus, davam a elas algum sentido, por mais precário que esse fosse. Mas, à medida que a ação se desenvolve, elas acabam se integrando bizarramente ao culto dos fragmentos da sociedade de consumo ${ }^{3}$, como veremos mais adiante.

Pois a decadência que lhes assoma parecer ser uma das consequências da modernização na periferia do capitalismo. Resulta tanto da destruição causada pelo elemento externo, os ciclos da economia mundial no Brasil, quanto do poder e da corrupção que deles derivam, nacionalmente localizados. Com efeito, o pano de fundo histórico de Cidade de Deus estaria composto de três ciclos curtos, não explícitos mas determinantes para a ação: i) os antecedentes da chegada dos habitantes do conjunto, tempos de escravidão, de terras cultivadas pelos portugueses; ii) a chegada dos primeiros caminhões de terra para transformar a antiga chácara em um conjunto residencial, metáfora do nacional-desenvolvimentismo, em que estava no ar justamente a promessa de desenvolvimento econômico; iii) a neofavela, com facções em luta pelo comando do tráfico de drogas, em uma referência à entrada do país no capitalismo tardio, financeirista e de desinvestimento total do Estado em políticas de bem-estar social. Esse ciclo inicia na década de 80, ganhando força máxima na de 90 .

Assim, ao captar literariamente essas passagens e seus efeitos, o romance plasma uma sociedade eternamente à deriva, dependente dos rumos do capital. Por isso é que, mesmo com a perspectiva histórica, e com o aumento gradativo da tensão, já se pressentem, desde o início da favela, os germens da derrocada social, entretanto mesclados à ideia de futuro venturoso para uma

3. Basta pensar que a personagem de Otávio comete os crimes vestido de cartola e fraque, como se fosse uma personagem de história em quadrinho ou desenho animado. 
população que se dirige a um lugar inabitado. Surge de chofre um sentido de comunidade integrada à força, sem regra e sem tecido social mais ou menos coerente, mimetizada na enumeração caótica a seguir, a respeito dos bens que os favelados trouxeram consigo às terras d'antes cultivadas pelos imigrantes portugueses:

lixo, latas, cães vira-latas, exus e pombagiras em guias intocáveis, dias para se ir à luta, soco antigo para ser descontado, restos de raiva de tiros, noites para velar cadáver, resquícios de enchentes, biroscas, feiras de quartas-feiras e as de domingos, vermes velhos em barrigas infantis, revólveres, orixás enroscados em pescoços, frango de despacho, samba de enredo e sincopado, jogo de bicho... (LINS, 1997, p. 18).

O poético (forma) e o prosaico (conteúdo) se articulam e precedem o que o narrador enunciará na sequência: uma nova comunidade, formada pelos resíduos da civilização, remanescentes seja do passado nas favelas de origem daqueles indivíduos proletarizados que foram para a Cidade de Deus, seja do espaço rural decadente, que produziu seus párias. Trata-se de uma comunidade "forçosamente estabelecida". Além de contar com a força (bruta, digase de passagem) do Estado, que jogou a população nos cafundós, ela surge também "através de brigas, jogos de futebol, bailes, viagens diárias de ônibus, da frequência aos cultos religiosos e às escolas". As brigas, situadas no início dessa outra breve enumeração, e fundamento da comunidade de Cidade de Deus, correspondem ao modo de sustentação da liderança que se vincula principalmente ao poder de usar a violência contra o outro:

os adolescentes utilizavam-se da fama negativa da favela onde haviam morado para intimidar os outros em caso de briga ou até mesmo nos jogos, na pipa voada, na disputa de uma namorada. Quanto maior a periculosidade da favela de origem, melhor era para impor respeito... (LINS, 1997, p. 35).

Em suma, a comunidade recém surgida se fundamenta na violência, e a lógica brutal, tanto do Estado quanto dos próprios moradores, é a que impera. De modo que a função do lírico no romance, além de apontar para o aprofundamento da situação, que se torna cada vez mais dramática - não custa 
lembrar que o traço dramático dominará Cidade de Deus a partir da terceira parte - traz a ideia de uma esperança que se frustra, e de que o sentido da derrota estava dado desde o início da "comunidade".

\section{Consumismos}

Como última etapa deste ensaio, o foco deve recair sobre a articulação, em Cidade de Deus, de um conjunto de referências arcaicas com outras da sociedade de consumo, que passam a fazer parte do modo de ser das personagens desse romance, sem com isso eliminar a violência intestina, muito pelo contrário; pois, em Cidade de Deus não apenas os bens de consumo estão presentes aos olhos de todos os habitantes, ajudando a construir seus modos de ser e acirrando a competição entre eles, como também as formas da cultura que embalam esses bens, veiculadas pela indústria cultural, constituem mediações simbólicas para tudo, até mesmo para a morte, que por vezes se reveste de ritual arcaico e simulacro pós-moderno. Roberto Schwarz, em sua leitura do romance, foi preciso também nesse ponto:

O apuro da coreografia combina-se à indistinção entre o bem e o mal. Quando trocam tiros, a autoridade e os bandidos põem 'meia cara na quina da esquina'. O acerto da expressão, com rima interna e tudo, faz pensar que não só a arte decanta a vida como também a vida se inspira nos seriados de televisão a que bandidos e policiais assistem (1999, p. 164).

Nesse sentido, não deixa de ser interessante observar que na segunda parte de Cidade de Deus os encontros momentâneos entre os traficantes e os jovens remediados da favela (cocotas) sejam propiciados por objetos de desejo comuns: roupas de grife, itens de consumo e drogas, envoltos muitas vezes pelo imaginário do American way of life. Por isso é que, num festival de rock a que foram, os cocotas "se drogaram de fumo, cocaína, pico e chá durante as setenta e duas horas de rock'n'roll comendo solto dia e noite em Magé": "sempre ouviram falar que rock'n'roll, muito mais do que um gênero musical, era uma maneira de viver” (LINS, 1997, p. 239). Por isso, também, Bené, o bandido parceiro de Zé Pequeno, de bicicleta, 
Seguia Daniel de longe, admirando seu jeito, vendo a sua beleza realçada pelo sol. Sentia inveja quando o cocota parava para dar beijinhos nas garotinhas mais bonitas da favela, fazia de tudo para não ser percebido ao segui-lo. Queria ser bonito, andar vestido como os cocotas, namorar aquelas meninas que andavam com eles, que pareciam felizes como ricos: queimados de sol, cabelo parafinado, tatuagem no corpo. Continuava a seguir Daniel pela rua Principal, tentando entender o que estava escrito em seu tênis, em sua camiseta e no short (LINS, 1997, p. 276).

Ao se aproximar dele, e depois de apostarem uma corrida, que o cocota espertamente deixa Bené ganhar, este pergunta ao outro onde comprou o seu tênis, a sua camisa, o seu short, e se, caso lhe desse dinheiro, compraria também para ele os mesmos produtos. O cocota responde que sim e, no mesmo dia, "a madrugada já era alta quando Bené acabou de experimentar as dezenas de shorts, camisetas e pares de tênis que Daniel lhe entregara no início da noite nas imediações do Bloco Sete. Agora só faltavam as calças Saint-Tropez". Em troca do serviço, "Daniel recebeu bagulho solto, além de uma quantia em dinheiro que nunca tinha colocado na carteira. Dava até para comprar uma prancha, ou um skate importado" (LINS, 1997, p. 277). Em seguida, numa próxima investida, o bandido buscaria se aproximar dos cocotas por meio de Daniel: "para isso passara a mandar maconha para a cocotada de manhã, de tarde e de noite, em todos os dias da semana, e também a pagar sorvetes, rocamboles e refrigerantes na Padaria Del Rei, onde costuma encontrar a turma reunida" (LINS, 1997, p. 282). E, enfim, se tornaria amigo deles: "chegavam a passar três dias juntos consumindo cocaína, ficavam acampados nas cidades da Costa Verde até enjoarem, iam à praia, discotecas e cinemas; vez por outra, passeavam na Zona Sul" (LINS, 1997, p. 350). Ou seja, a relação é sustentada pelo intercâmbio entre a droga, os produtos e o gosto mais sofisticado, ou então, "americanizado", dos cocotas, que os bandidos queriam aprender e fruir. Nas palavras do narrador,

O movimento das bocas-de-fumo não parava de crescer, o consumo de cocaína aumentava a cada dia. Os viciados da favela ou de fora, na ânsia da droga, apareciam na boca com cordões, alianças, pulseiras, televisores, relógios, revólveres, batedeiras, liquidificadores e tantos outros eletrodomésticos para 
trocar por cocaína. Os mundos em cruzamento possibilitavam cambiar-se tudo (LINS, 1997, p. 351).

Entretanto, mesmo que Bené desejasse e conseguisse em alguns momentos curtir a vida ao lado dos adolescentes de classe média, a sua existência será curta, ao contrário da daqueles. E o seu fim será decretado por seu passado, do qual não consegue escapar, por mais que, sonhador, almejasse sair da favela e fundar junto com os cocotas uma sociedade alternativa. Assim, depois da festa de ano novo que passa com eles, Bené morrerá pelas mãos de Botucatu. Este, que cometera um crime bárbaro com a ex-namorada, fizera-o na favela, e fora espancado por Zé Pequeno. Bené foi quem impediu que seu amigo matasse Botucatu, que apesar de executar a ex-namorada nas redondezas, fez, segundo o bandido bom, algo que era "seu contexto", isto é, lavou sua honra. Buscando se vingar de Zé Pequeno, Botucatu se esconde para matá-lo, mas erra a mira e atinge o outro, Bené. O lance de tragédia simboliza ao final da segunda história, que é a "A história de Bené", não só o fim do marginal herói, mas também as assimetrias culturais entre os dois mundos, dos malandros e dos cocotas, do tradicional e do moderno, do campo e da cidade. Não que em vários níveis, ao longo da história, não houvesse trocas - "intercâmbios" - e admirações mútuas de parte a parte. De todo o modo, o abismo social se solidifica, por mais que as trocas culturais aconteçam. ${ }^{4}$

A terceira parte de Cidade de Deus inicia com um longo diálogo entre viciados em que se percebe com bastante evidência a desagregação do espaço já pressuposta, tanto pela referência ao sumiço de Busca-Pé, uma das únicas personagens pobres que conseguem ascender de classe, quanto pela descrição de uma briga entre um favelado e um playboy, por motivo banal. Além do mais, é nessa parte que um trabalhador honesto, Mané Galinha, vai vingar a sua ex-namorada, vítima de estupro de Zé Pequeno, e a sua família, praticamente exterminada pelo bando deste, saindo do mundo da ordem em que estava para cair definitivamente no mundo da desordem. Vale ler o início do referido diálogo:

4. Uma formalização artística mais recente desse processo paradoxal é o filme Quase dois irmãos, de Lucia Murat, com roteiro do próprio Paulo Lins. Nele, uma filha-família sobe o morro pelo fascínio por sua cultura funkeira e por um chefe do tráfico. Na cena final, a moça será estuprada por indivíduos da facção rival, alegorizando, como o "quase" do título, a impossibilidade do encontro. 
- Busca-Pé sumiu!

- É... Ta sumidão!

- O cara se destacou mermo, né?

- Pode crer!

- Só vejo ele passando...

- Ele tá colado com aquele pessoal do Conselho de Moradores...

- Ele virou retratista mermo!

- Pode crer! (LINS, 1997, p. 390)

O diálogo ininterrupto, com frases breves, continua por mais seis páginas, sugerindo, além do estilo da conversa de viciados, o laconismo de informações sobre o destino das personagens remediadas do lugar, que o abandonam, rumo a outros espaços: “(...) todo mundo sumiu! Só quem tá na pista é a gente mermo... assim, que anda junto..." (LINS, 1997, p. 390). Ou seja, quem sobrou foram os pobres e os traficantes. E se Busca-Pé, personagem honesto, culto, admirado por todos, "some", isso significa talvez que não haja mais chance de outros iguais a ele naquele lugar. Significa, ainda, que dos anos 1980 em diante, que a terceira parte do romance busca apreender, desaparece completamente a esperança de se mudar de classe, ou mesmo de se educar. Nesse momento, também, o "namoro" entre traficantes e cocotas parece ter acabado. Vejamos o outro fragmento do longo diálogo:

- Um moleque, rapá... playboy... Acho que era lá do Pau Ferro. Chegou lá nos Apê perguntando onde era a boca, sabe qual é? Aí, Biscoitinho falou que tava endolando... Aí, o moleque foi ali nas lojinha, pediu uma Coca e um maço de cigarro... Israel tá olhando ele... Doidão, cumpádi, doidão de goró!

- Quando ele bebe, ele adora rumar arengação. 
- O moleque pintosão (...) ... Aí ele acendeu o cigarro, colocou o isqueiro assim em cima do balcão e ficou ali, na dele, tomando a Coca. Cumpádi! Quando ele foi pegar o isqueiro, Israel deu maior tapão na cara dele, aí. Ele tava só olhando o cara de banda...

- Quando ele pegou o isqueiro, ele deu um pulo e plantou a mão na cara do playboy e mandou assim: 'Quer roubar meu isqueiro? O isqueiro é meu'. O playboy foi falar que o isqueiro era dele, cumpádi! Ele só deu de 9 na testa, aí: desfigurou o cara todinho! (LINS, 1997, p. 394)

A gratuidade da ação e a inveja da beleza do outro, que humilha o pobre coitado, substituem de vez aquelas tentativas de diálogo a partir da troca de mercadorias, ainda vislumbradas nos anos 70. Entretanto, não desaparece o interesse pelos mesmos objetos, cada vez mais inalcançáveis, mas, por outro lado, cada vez mais visíveis. O tomar posse do isqueiro simboliza o desejo por todos os bens que não possui. Não em vão, a forma brutal de vingança consistiu em um tiro no rosto do playboy, talvez para que se quebre o espelho em que Israel não consegue parar de se refletir.

\section{Referências bibliográficas}

AREAS, Vilma. Errando nas quinas da Cidade de Deus. In: Praga: estudos marxistas, São Paulo: 5: 147-158, 1998.

CANDIDO, Antonio. Literatura e subdesenvolvimento. In: A educação pela noite e outros ensaios. São Paulo: Atica, 1989.

FINLEY, M. I. O mundo de Ulisses. Trad. Armando Cerqueira. Lisboa; São Paulo: Presença; Martins Fontes, 1972.

FRYE, Northrop. Anatomia da crítica. Trad. Péricles Eugênio da Silva Ramos. São Paulo: Cultrix, 1973.

HOMERO. Ilíada. Trad. Carlos Alberto Nunes. Rio de Janeiro, Ediouro, 1991.

JAMESON, Fredric. Pós-modernismo: a lógica cultural do capitalismo tardio. Trad. Maria Elisa Cevasco. São Paulo: Ática, 1996.

LINS, Paulo. Cidade de Deus. São Paulo: Companhia das Letras, 1997.

SCHWARZ, Roberto. Sequências brasileiras. Companhia das Letras: São Paulo, 1999.

Recebido em 15 de agosto e aprovado em 25 de setembro de 2010. 